\title{
El populismo en Chile: ¿tan lejos o tan cerca?
}

\author{
Populism in Chile: So Far or So Close?
}

\author{
Alexis Cortés* \\ Alejandro Pelfini**
}

\begin{abstract}
Resumen
El populismo no es sólo un fenómeno político, es también un indicador de la porosa relación entre ciencias sociales y sociedad. No se puede estudiar el populismo sin tematizar el carácter performador de estas disciplinas en la construcción de ese debate. Este artículo propone una revisión crítica de la producción reciente de las ciencias sociales sobre el populismo en Chile a partir de tres interpretaciones y tres intervenciones públicas que contradicen la idea de que este país está lejos de cualquier tradición populista, transformando al populismo en una categoría política central de las disputas públicas chilenas.
\end{abstract}

Palabras clave: populismo, excepcionalidad chilena, performatividad

\begin{abstract}
Populism is not only a political phenomenon, it also represents the porous relationship between social sciences and society. One can hardly study populism without taking in account the performative character of these disciplines in the construction of this debate. This paper proposes a critical review of the recent production of social sciences on populism in Chile based on three interpretations and three public statements that contradict the idea that this country is far from any populist tradition, transforming populism in a key political category in the current public disputes in the country.
\end{abstract}

Keywords: populism, Chilean exception, performativity

Recibido: 31 agosto 2016

Aceptado: 12 diciembre 2016

\footnotetext{
Chileno, primer autor, Doctor en Sociología IESP-UERJ (Brasil), Académico del Departamento de Sociología Universidad Alberto Hurtado, Proyecto FONDECYT nº11140336, cortes.alexis@ gmail.com

**Argentino, segundo autor, Doctor en Sociología (UniversitätFreiburg, Alemania), Académico del Departamento de Sociología Universidad Alberto Hurtado, Director del Módulo Latinoamericano del Programa de Estudios Globales en FLACSO-Argentina, Proyecto FONDECYT n¹1141001, apelfini@uahurtado.cl
} 


\section{El fantasma del populismo y las ciencias sociales en América Latina}

Cuando Marcos Roitmann" describía la "maldición" del pensamiento sociológico latinoamericano, buscaba denunciar la inclinación de esa disciplina a reducir la trayectoria del continente a la modernidad a un desvío incorrecto del movimiento realizado por los países europeos o de los Estados Unidos. América Latina se caracterizaría por la ausencia, por lo que tiene de incompleto o por lo que le falta para aproximarse a estas referencias. Ahora bien, pareciese que esa "maldición" teórica tiene una correspondencia en la política. El populismo, como amenaza permanente, representaría la concreción de todos los desvíos no deseados para la constitución de un campo político moderno en los países latinoamericanos. El fantasma del populismo para la democracia en la región ha sido uno de los tópicos más recurrentes en las ciencias sociales para describir la ola de gobiernos post-neoliberales. Sin embargo, bien cabe la pregunta: ¿es el populismo la "maldición" política del continente o es el pensamiento político que estudia América Latina el que tiende a reducir los fenómenos políticos que no encajan en el imaginario occidental de la política moderna a las lógicas populistas? En el ejercicio de inversión epistemológica hecho por Guilherme Simões Reis ${ }^{2}$, al relatar un siglo de historia política europea como si fuese América del Sur, está latente, aunque de manera irónica, una posible respuesta.

En un trabajo anterior", se planteó que tanto el concepto de "elite" como el de "populismo", incluso habiendo sido categorías claves para la reflexión de las ciencias sociales en América Latina, han vivido la desventura de experimentar un uso reciente de carácter inflacionario. El populismo, concepto que durante buena parte del siglo XX permitió explicar y comprender complejos procesos políticos de incorporación de amplios sectores sociales postergados a la vida política, actualmente es utilizado, por parte importante de las ciencias sociales, por la prensa y por los actores políticos como sinónimo indistinto de demagogia. Este abuso del concepto coincidiría paradojalmente con lo que allí se entendía como un uso "elitista" del término populismo: "los populistas son siempre otros, anómalos e incurables a los que se atribuye persistir cínicamente en mezclar en forma extravagante, y para provecho propio, lo político y lo social, esferas que el neoliberalismo y el institucionalismo se habían ocupado de separar para siempre"4. Este uso elitista reproduce la lógica de la existencia de las dos izquierdas": una "buena" izquierda más próxima de la tercera vía británica, preocupada con los equilibrios macroeconómicos, con la realización de reformas en la medida de lo posible, respetando estrictamente la institucionalidad nacional; mientras que, la izquierda "equivocada", sería post-neoliberal,

\footnotetext{
${ }^{1}$ Marcos Roitman Rosenmann, Pensar América Latina. El Desarrollo de La Sociología Latinoamericana, Buenos Aires, CLACSO, 2008.

${ }^{2}$ Guilherme Simoes Reis, "Um Século de Política Europeia (Contado como se fosse na América Do Sul)", Insight Inteligência, 16:64, 2014, 91-98.

3 Alejandro Pelfini, 'Uso Inflacionario de Los Conceptos 'Elite' Y 'Populismo': Desventuras Recientes de Dos Categorías Claves de Las Ciencias Sociales Latinoamericanas”, Tomás Ariztía (ed.), Produciendo Lo Social: Usos de Las Ciencias Sociales En El Chile Reciente, Santiago, Ediciones Universidad Diego Portales, 2012, 197-217.

${ }^{4}$ Pelfini, op.cit., 198.

5Jorge Castañeda, “Latin America’s Left Turn”, Foreign Affairs, 85:3, 2006.
} 
con proyectos refundacionales apoyados en líderes personalistas que no respetarían las institucionalidades de sus respectivos países.

Para Enrique Dussel ${ }^{6}$, este uso "elitista" corresponde más bien a lo que clasifica como un "seudo-populismo" que transforma la categoría en un epíteto peyorativo que esconde una crítica política conservadora, neutralizando su validez epistémica:

Se había producido un deslizamiento semántico, una redefinición político estratégica del término. Ahora "populismo" significa toda medida o movimiento social o político que se proponga a la tendencia de globalización tal como la describe la teoría de base del "consenso de Washington", que justifica la privatización de los bienes públicos de los Estados periféricos, la apertura de sus mercados a los productos del capital del centro, y que niega la priorización de los requerimientos, de las necesidades de las grandes mayorías de la población, empobrecida por las políticas adoptadas por las dictaduras militares (hasta aproximadamente 1984) y aumentadas posteriormente por las decisiones de reformas estructurales dictadas desde los criterios de una economía neoliberal ${ }^{7}$.

Todo desvío del proyecto neoliberal es identificado como "populismo" y nada diferenciaría su uso de un insulto destinado a desacreditar a las perspectivas políticas que se proponen la superación de las lógicas económicamente neoclásicas de regulación de la vida social. Los estudios sobre populismo responderían a una colonización ideológica (neoliberal y eurocéntrica) de las ciencias sociales. Por lo mismo, estas disciplinas deberían simplemente abandonar su utilización, por la ausencia de claridad semántica y por su contenido epistémico impreciso.

Tal como señalan Dockendorff y Kaiser $^{8}$ en una amplia y extensa revisión de la literatura sobre populismo en América Latina, existe cierta correspondencia entre el carácter ideológicamente laxo del populismo y la imprecisión conceptual de la academia para definir el populismo como fenómeno. En el tratamiento de las ciencias sociales, los estudios fluctúan entre la saturación del término, aglomerando una gran cantidad de atributos que sobrecargan el populismo de significados y que lo distancian de fenómenos empíricos históricos; y las definiciones minimalistas que omiten cualidades significativas del mismo 9 . Aunque consideren el populismo como una materia pendiente en el estudio de la política latinoamericana, las potencialidades analíticas del término residirían en cómo las ciencias sociales conciben y precisan sus lentes de aproximación a la realidad y en la superación de las tendencias saturadoras y minimalistas del concepto: "El punto ciego en el estudio de la política latinoamericana desde el populismo es la inexistencia de un acuerdo o

\footnotetext{
${ }^{6}$ Enrique Dussel, “Cinco Tesis Sobre El 'populismo”,, Iztapalapa, 2007, http://enriquedussel.com/txt/Populismo.5\%20tesis.pdf

${ }^{7}$ Dussel, op.cit., 4.

${ }^{8}$ Andrés Dockendorff y Vanessa Kaiser, "Populismo En América Latina. Una Revisión de La Lieratura y La Agenda", Revista Austral de Ciencias Sociales, 17, 2009, 75-100.

${ }^{9}$ Kurt Weyland, "Clarifying a Contested Concept: Populism in the Study of Latin American Politics", Comparative Politics, 34:1, 2001, 1-22.
} 
punto de convergencia que delimite y segmente los atributos y características excluyentes del término populismo" $"$.

Pareciera ser que el populismo nos dice mucho más de la relación porosa que establecen las ciencias sociales con la sociedad (y el mundo político en particular), y menos de un fenómeno exclusivamente político. El populismo evidencia la "doble hermenéutica" existente entre ciencias sociales y el mundo social, o sea, un proceso de reflexividad bidireccional que, por lo tanto, afecta a ambos términos de la relación. El trabajo analítico de las ciencias sociales se hace a partir de un mundo "pre-interpretado", en el cual los sujetos de estudio de los cientistas sociales poseen las mismas habilidades cognitivas de creación y recreación de los cuadros de significado que constituyen la vida social. De esta manera, existe un permanente ir y venir de conceptos, interpretaciones y sentidos entre el mundo lego y el mundo científico que terminan por modificar las comprensiones mutuas que estas esferas tienen.

hay un continuo 'deslizamiento' de los conceptos construidos en sociología, mediante el cual se apropian de ellos los individuos para el análisis de cuya conducta fueron originariamente acuñados, y por consiguiente tienden a convertirse en rasgos integrales de esa conducta (modificando potencialmente, de este modo, su empleo original dentro del vocabulario técnico de la ciencia social) ${ }^{11}$.

La idea del "desvío" conceptual del populismo alerta sobre el grado de influencia de la definición lega en lo usos y abusos que las ciencias sociales realizan del término, pero al mismo tiempo asume que esta permeabilidad está presente prácticamente en cualquier ejercicio interpretativo de las ciencias sociales. ¿Podemos renunciar al "populismo" como categoría clave para comprender la política latinoamericana al considerar el antecedente inflacionario de su uso?

Una respuesta es la de Laclau ${ }^{12}$, para quien el populismo es un modo de construir lo político, siendo más una lógica que atraviesa varios fenómenos y menos un fenómeno de límites claros. De ahí la dificultad para encontrar una unidad referencial para el mismo. Este intento de positivización del populismo, aunque haya renovado provechosamente el campo de estudios, no resuelve el problema empírico del imaginario que las propias ciencias sociales producen, contribuyendo indirectamente al levantamiento de discursos apologéticos de gobiernos que pueden ser identificados con las lógicas descritas en su obra. Otra respuesta posible es la perspectiva "no normativa" del populismo que, reconociéndolo como una acción y discurso válidos entre otros posibles, como cualquier otra tradición política posee contradicciones y ambigüedades que deben ser comprendidas contextualmente $^{13}$. Bajo esta visión, el populismo aparece dotado de una ambivalencia que

\footnotetext{
${ }^{10}$ Dockendorff y Kaiser, op.cit., 96.

${ }^{11}$ Anthony Giddens, Las Nuevas Reglas Del Método Sociológico, Buenos Aires, Amorrortu, $1987,166$.

${ }^{12}$ Ernesto Laclau, La Razón Populista, Bueno Aires, FCE, 2005.

${ }^{13}$ Alejandro Pelfini, "Megatrend Global Populism? From South America to the Occupy Movement", Alexander Lenger y Florian Schumacher (eds.), Understanding the Dynamics of Global Inequality: Social Exclusion, Power Shift, and Structural Changes, Berlin - Heildelberg, Springer, 2015, 199-211.
} 
lo transforma tanto en amenaza como posible correctivo de la democracia ${ }^{14}$. En el populismo, convivirían la potencial conformación de regímenes autoritarios y la posibilidad de democratización de sistemas institucionales excluyentes.

El populismo representa simultáneamente la regeneración de los ideales participativos y de igualdad de la democracia, así como la posibilidad de negar la pluralidad de lo social, pero sin esta pluralidad, el ideal democrático puede degenerar en formas autocráticas y plebiscitarias de aclamación a un líder construido como la encarnación de la voluntad unitaria del pueblo. ${ }^{15}$

A su vez, Mackinnon y Petrone ${ }^{16}$ abogan por una "cenicienta sin complejos" superando la mirada negativa respecto del populismo por una afirmativa "identificando lo que hay y no lo que no hay" así como una articulación de rasgos: "los atributos que podrían conformar esta unidad analítica mínima son los siguientes: a) la crisis como condición de emergencia; b) la experiencia de participación como sustento de la movilización popular; y c) el carácter ambiguo de los movimientos populistas". ${ }^{17}$

Sin duda, estas perspectivas vienen enriqueciendo aún más los debates sobre este fenómeno político. Sin embargo, desde el punto de vista defendido en este texto, la comprensión del populismo es inseparable de los efectos que las ciencias sociales provocan con sus usos y abusos conceptuales ${ }^{18}$ en la configuración de imaginarios sobre el mismo. No se puede estudiar el populismo sin tematizar a las ciencias sociales como intervinientes en la performación de los procesos que busca describir ${ }^{19}$. Precisamente, lo que aquí se propone es hacer una revisión crítica de la producción reciente de las ciencias sociales sobre el populismo en Chile a partir de tres interpretaciones que contradicen la idea de que este país andino está lejos de cualquier tradición populista. Efectivamente, Chile es un país que ha sido mostrado por la academia y por la prensa internacional durante las últimas dos décadas como el paradigma de un sistema político-económico adverso al populismo por su transición democrática ejemplar ${ }^{20}$, pero donde también el fantasma del populismo aparece como una posible amenaza en los discursos de diferentes sectores políticos. ¿Cómo las ciencias sociales en Chile han procesado el espectro del populismo? Analizando

\footnotetext{
${ }^{14}$ Cristóbal RoviraKaltwasser, "The Ambivalence of Populism: Threat and Corrective for Democracy", Democratization, 19:2, 2012, 184-208.

${ }^{15}$ Carlos de la Torre, "El Populismo Latinoamericano: Entre La Democratización Y El Autoritarismo", Nueva Sociedad, 247, 2013, 137.

${ }^{16}$ María Moira Mackinnon y Mario Alberto Petrone: "Los complejos de la cenicienta", introd. a Mackinnon y Petrone (Eds.): Populismo y Neopopulismo en América Latina. El problema de la Cenicienta. Buenos Aires, Eudeba, 1998, 11-55.

${ }^{17}$ Mackinnon y Petrone, Op.cit., 45.

${ }^{18}$ Elisabeth Simbürger, "The Labor of Knowledge in the Making of the Social Sciences," International Sociology, 29:2, 2014, 89-97.

${ }^{19}$ Claudio Ramos, "Datos Y Relatos de La Ciencia Social Como Componentes de La Producción de Realidad Social”, Convergencia, 21:66, 2014, 151-77.

${ }^{20}$ Manuel Castells, Globalización, Desarrollo Y Democracia: Chile En El Contexto Mundial, Santiago, Fondo de Cultura Económica, 2005; Alain Touraine, "Éxitos y Límites de La Democratización en América Latina”, Estudios Sociológicos, 16:48, 1998, 745-60.
} 
críticamente tres lecturas sobre el populismo en Chile, así como las derivaciones públicas de este debate, se espera ensayar una respuesta a esta pregunta.

\section{El populismo en el retrovisor: ¿más próximo de lo que aparenta?}

El mito de la excepcionalidad chilena es una de las construcciones político-académicas que más marcaron el imaginario de la trayectoria política de este país durante el siglo XX. Según esta construcción, la institucionalización de los conflictos sociales mediante un sistema de partidos que llegaron a transformarse en constructores identitarios casi tan importantes como las propias clases sociales y el respeto por el Estado de Derecho permitió que tempranamente el espacio del conflicto fuese regulado por canales democráticos ${ }^{21}$. Partidos políticos fuertes y de larga tradición eran una especie de columna vertebral de la vida política y social, los que impedían que los Golpes de Estado y los proyectos populistas encontrasen terreno fértil para su expansión. Este relato fue desmitificado parcialmente con el golpe de Estado del General Pinochet en 1973, sin embargo la atribución de una especie de inmunidad chilena frente al populismo ha persistido hasta nuestros días ${ }^{22}$.

Sin embargo, el trabajo del historiador Joaquín Fernández ${ }^{23}$ cuestiona esta visión mediante el estudio sistemático de la trayectoria política del General Calos Ibáñez del Campo, particularmente en el periodo que va desde 1937 a $1952 .{ }^{24}$ Según este historiador, el populismo en cuanto expresión política de la cultura nacionalista presente en el marco de una sociedad de masas en vías de desarrollo puede ser comprendido de la siguiente manera:

como un movimiento político reunido en torno a un líder carismático, quien, identificándose con la totalidad del pueblo, pretende congregar grandes masas de adherentes. El nacionalismo populista tiende a asimilar la patria con el pueblo, pretendiendo extraer su legitimidad de dicha fuente. En el marco del populismo, la definición de pueblo apunta a las grandes mayorías, representadas por la gente común, y a sus tradiciones, en las que residiría la virtud. Estas características inciden en que el populismo tienda a la integración social y llame a la cooperación entre clases, rasgos que lo facultan para emprender tareas tan disímiles como denunciar la agitación comunista o las oligarquías egoístas. En esta versatilidad populista incidiría su laxitud y eclecticismo ideológico. Los movimientos populistas poseen un fuerte moralismo, orientado hacia la

\footnotetext{
${ }^{21}$ Manuel Antonio Garretón, Dictaduras Y Democratización, Santiago, FLACSO, 1984.

${ }^{22}$ Claudio Riveros, "Populismo, democracia y democratización”. Persona y Sociedad, 29 (3), 2015, $103-126$.

${ }^{23}$ Joaquín Fernández, El Ibañismo (1937-1952): Un Caso de Populismo En La Política Chilena, Santiago de Chile, Instituto de Historia PUC Chile, 2007.

${ }^{24}$ Un antecedente de populismo podría encontrarse en la figura de Arturo Alessandri Palma, muchas veces considerado como populista por su (breve) caudillismo. Sin embargo, Verónica Valdivia ("Yo, el León de Tarapacá", Historia, Vol. 32. 1999: 485-551) demuestra que el estilo populista en la movilización de masas fue en Alessandri "sólo coyuntural y muy limitado, persiguiendo propósitos específicos ... La movilización popular fomentada por Alessandri fue una pantalla para lograr fines político-institucionales que le aseguraran su victoria." (p. 488) siendo abandonada en estilo y en temas (la cuestión social) una vez obtenido el triunfo electoral. Ante esto cabría preguntarse si a este caso le cabe la categoría populismo, cuando el acercamiento al pueblo y su movilización se reduce al "plano más bien emotivo y retórico, sin lograr articularse en antagonismo con la ideología liberal dominante, sino como una apuesta de democratización legalista” (p. 488); antagonismo que sí estaría presente en otros casos en la región unos años después.
} 
redención social, y tienden a identificar a sus enemigos como fuerzas perjudiciales de carácter antinacional. El personalismo y el maniqueísmo presentes en dichas posturas esencialistas hacen que el populismo, a pesar de su carácter integrador, se acerque hacia actitudes autoritarias. Por esto, si bien no es necesariamente antidemocrático, sí es antiliberal. ${ }^{25}$

Según la investigación de Fernández, entre 1937 y 1952, se generó una tendencia populista en torno a la figura de Carlos Ibáñez. El ibañismo "aspiró a transformarse en un movimiento de unidad nacional. Apelando al hombre común y sus valores, promovió la integración de los distintos sectores sociales en torno al liderazgo carismático de Ibáñez y a un proyecto político de contenido doctrinal variable, pero siempre caracterizado por un fuerte nacionalismo y por la exaltación del presidencialismo"26. La coincidencia con la completa definición hecha más arriba no terminaba sólo en eso, pues al mismo tiempo: "El ibañismo no se constituyó en un solo movimiento organizado, expresándose a través de movimientos independientes y corrientes en los partidos de las más diversas tendencias". El análisis de Fernández - al que puede sumarse el anterior trabajo de Grugel (1992) quien destaca el carácter democratizador del populismo ibañista - no sólo está a contracorriente del discurso académico que ha minimizado el papel jugado por el fenómeno populista, sino que además reivindica la actualidad del estudio del ibañismo en un contexto de crítica creciente por parte de la ciudadanía al sistema político, alertando sobre la influencia que este tipo de liderazgos pueden llegar a tener en una sociedad como la chilena.

Aunque no pretenda desconstruir el relato dominante en las ciencias sociales sobre el populismo, sino más bien desmitificar provocadoramente la figura de Salvador Allende, Carlos Cousiño ${ }^{27}$ analiza su gobierno desde la categoría del populismo, aunque reduciéndolo a su dimensión económica. El populismo es definido, por este sociólogo, como la respuesta típicamente latinoamericana a las demandas de consumo provocadas por el crecimiento demográfico y el aumento dramático de la marginalidad en las ciudades, provocados principalmente por las migraciones. El populismo tendría como trazo característico el exceso, sea tanto a nivel de una relación política sustentada en una retórica "virulentamente" anti-oligárquica, pero sobre todo en su inclinación a expandir el gasto público, subordinando la economía a la política y trayendo como consecuencia la crisis inflacionaria y la escasez. Desde este punto de vista,

La gran experiencia populista que conoce Chile fue la encabezada por Allende durante los tres años que duró el gobierno de la Unidad Popular. Y si algún error grave cometió Allende y la izquierda chilena fue precisamente no darse cuenta del fundamento populista de su legitimidad y haber creído que encabezaban un proceso revolucionario que conduciría a nuestra sociedad a la tierra prometida del socialismo. La fatalidad del gobierno de la Unidad Popular fue no entender al pueblo que representaban, fue haberse autoconvencido, cegado por los excesos ideológicos, de que conducían masas con conciencia

\footnotetext{
${ }^{25}$ Fernández, Op.cit., 24.

${ }^{26}$ Fernández, Op.cit., 21.

${ }^{27}$ Carlos Cousiño, "Populismo y Radicalismo Durante El Gobierno de La Unidad Popular," Estudios Públicos, 82, 2001, 189-202.
} 
revolucionaria de clase y no masa urbanas desamparadas que buscaban mejorar sus míseras condiciones de vida. ${ }^{28}$

El populismo, en esta interpretación, aparece negado por sus propios practicantes. El problema del gobierno de Allende habría sido no reconocerse a sí mismo como populista, cayendo en la radicalización política e ideológica, la cual era incompatible con la demanda de la base social de la Unidad Popular que aspiraba a una integración en el consumo a través de un proyecto político movilizante. Sería la promesa de integración y no la invocación revolucionaria lo que explicaba el apoyo social al gobierno. Resulta curioso considerar que esta interpretación no sólo reduce el populismo a una dimensión económica, como lamenta la no existencia de un liderazgo que hubiese sido capaz de evitar el laberinto político que culminó en el golpe de Estado. La salida frente a esta situación habría residido en la capacidad individual de un "hombre de Estado" que comprendiese la necesidad histórica de evitar el desastre que finalmente ocurrió. Paradojal es que el populismo económico allendista derivado en radicalismo, pudiese haber sido enfrentado con un tipo de acción política basado en las características extraordinarias de un actor, lo que normalmente es identificado como una de las principales características del populismo: "Cuando se mira en retrospectiva este período que nos es cercano biográficamente, pero lejano históricamente, no podemos sino detenernos a meditar sobre la falta que le hizo a nuestro país la figura de un gran estadista, de un gran político capaz de doblarle la mano a lo que se perfilaba como un ineludible destino trágico. Chile no tuvo a ese hombre"29.

Para Emanuelle Barozet ${ }^{30}$, el populismo en Chile como "estilo político" basado en un liderazgo personalista, sustentado en redes clientelistas y en una relación asistencialista con el Estado, tiene muchos más cultores de lo que la autoimagen del país que política y económicamente se escapa de las lógicas del vecindario, desearía admitir. ¿Cómo emergen y subsisten dinámicas populistas en un contexto de modernización política y crecimiento económico sostenido? Para responder esta cuestión, según la autora, hay que ir más allá del imaginario exaltante de la modernización y situar el lente investigativo en los liderazgos locales, sobre todo los municipales, tradicionalmente descuidados por las ciencias sociales. Así,

Más allá de la macro-economía y de la macro-política, se puede observar una serie de fenómenos más cercanos al imaginario de la política latinoamericana: casos de corrupción, grandes dificultades técnicas en la modernización del Estado, persistencia e incluso agravación de las desigualdades. También, la perduración en la política local y regional de verdaderos caudillos, dirigentes hegemónicos que no parecen seguir la corriente general de la modernización política del país o que se aprovechan de ella para perpetuarse en el poder. ${ }^{31}$

Estos líderes populistas construirían su base social a través de la instrumentalización de redes y vínculos sociales duraderos, sean verticales u horizontales, sean formales o

\footnotetext{
${ }^{28}$ Cousiño, Op.cit., 195.

${ }^{29}$ Cousiño, Op.cit., 201.

${ }^{30}$ Emmanuelle Barozet, "Movilización de Recursos Y Redes Sociales En Los Neopopulismos: Hipótesis de Trabajo Para El Caso Chileno”, Revista de Ciencia Política (Santiago), 23:1, 2003, 39-54.

${ }^{31}$ Emmanuelle Barozet, "Populismo regional y estado en Chile”, Estudios Interdisciplinarios de América Latina y el Caribe, 19:2, 2008, 46.
} 
informales principalmente con los sectores populares. Aquí reaparece la promesa de satisfacción inmediata de las necesidades populares como principal componente de la acción política que permite el establecimiento de una red clientelista de apoyo electoral.

Aunque las estructuras partidarias son vistas como un engranaje formal de su soporte, su eficacia electoral descansa más en redes sociales de carácter informal y por lo mismo más invisibles, aunque extremamente eficientes en la distribución de recursos públicos. La menor visibilidad de las políticas locales en la política chilena y la existencia de políticas públicas de carácter focalizado darían a las autoridades regionales un amplio margen de maniobra para distribuir arbitrariamente el acceso a los beneficios del Estado, con un alto impacto en la vida de los ciudadanos más pobres, lo que reforzaría la constitución de espacios de proximidad directa entre el líder populista y sus representados. La maquinaria municipal se transforma en un dispositivo de circulación de bienes y servicios que no anula formas de participación local, sino que más bien las instrumentaliza a través de dinámicas de vinculación rutinizadas:

La necesidad de satisfacer los problemas de bienestar material (en especial conseguir alimentos, casa, trabajo, medicamentos, cuidados, agilizar documentos) implica que son las redes rutinarias de solidaridad las que están en movimiento, aunque estén inmersas en una lógica clientelar. Establecer vínculos sociales y sobre todo de confianza toma tiempo, en especial en zonas urbanas pobres y violentas, por lo que no se puede justificar la existencia de vínculos clientelares desconectados de las redes rutinarias de ayuda. La oposición entre la lentitud de los canales oficiales (municipalidad y servicios asociados) y la inmediatez de la activación de las redes informales remite al discurso neopopulista, cuando promete la resolución inmediata de los problemas. ${ }^{32}$

Se podría decir, a partir de lo expuesto por Barozet, que la propia modernización económica neoliberal que, en el ámbito de las políticas públicas, estimuló lógicas de focalización por sobre gramáticas de derechos sociales, ha facilitado la apropiación de ciertos dispositivos públicos por parte de líderes populistas, prácticas tradicionalmente asociadas a lo políticamente anti-moderno. Sin duda, el mérito de la investigación de la académica de la Universidad de Chile es romper el relato chileno autocomplaciente que ha primado desde el retorno a la democracia, el que sitúa la trayectoria política y económica del país en una senda completamente diferente de los países de la región; mostrando, al mismo tiempo, la potencialidad analítica de la categoría populismo en un contexto supuestamente adverso a su empleo. Sin embargo, cabe preguntarse lo siguiente: ¿Cómo la desmitificación de la idea de un país inmune al populismo no engendra una nueva mistificación que identifica cualquier forma de personalismo político o de relación asimétrica con los sectores populares como populismo?, ¿acaso esto no podría dar paso a una nueva forma de confundir populismo con demagogia? Aunque en la investigación de Barozet son dos formas de liderazgo municipal ideológicamente en campos opuestos y además geográficamente distantes los que son analizados, entre otras razones porque la construcción de redes clientelistas por parte de liderazgos municipales fuertes estuvo

\footnotetext{
${ }^{32}$ Barozet, “Movilización de Recursos Y Redes Sociales En Los Neopopulismos”, 52.
} 
presente en las dos grandes coaliciones que dominaron la transición ${ }^{33}$; sólo una de esas experiencias tuvo una repercusión nacional. Nos referimos a Joaquín Lavín, ex alcalde de la Municipalidad de Santiago que disputó la elección presidencial de 1999-2000 en representación de la derecha conservadora contra el militante socialista Ricardo Lagos, siendo éste electo en una segunda vuelta por un escaso margen. Esta elección podría ser fácilmente leída como el enfrentamiento entre dos lógicas políticas opuestas: el liderazgo neo-populista lavinista que enarbolaba un discurso público desideologizado y pragmático, orientado a solucionar los problemas "reales" de las personas; versus la de un político más tradicional con una carga ideológica progresista fuerte, cuyo lema era "crecer con igualdad". Tal como fue mostrado por un grupo de investigadores chilenos ${ }^{34}$ en una encuesta aplicada en la capital del país, al analizar el perfil de los electores de Lagos y Lavín quedó en evidencia que, a pesar del debilitamiento del clivaje de clase, por la penetración lavinista en el electorado popular (principalmente femenino); se fortaleció y amplió el clivaje político clave de la transición democrática: la posición histórica adoptada en relación al plebiscito que le puso fin a la dictadura militar en 1988. Así, quien votó "no" a la dictadura tendió a votar por Lagos; mientras quien votó "sí", tendió a hacerlo por Lavín, lo que, en un contexto de envejecimiento del padrón electoral (la mayor parte de los jóvenes chilenos no se inscribía en los registros electorales, acto que en aquel entonces era voluntario), sería determinante. El lavinismo como forma de neo-populismo que se afirma como superación de binomio izquierda-derecha y pretendía comprender la política desideologizadamente no fue capaz de superar un clivaje extremamente político. ¿Se puede entender entonces el fenómeno del lavinismo apenas desde una noción de populismo que lo entiende como "estilo de hacer política"?

Incluso si situamos la mirada no ya en la elección presidencial, sino en la política municipal misma, veremos que en el propio nicho electoral de Lavín, la municipalidad de Santiago, se conformó una estructura de relaciones clientelistas, intercambios simbólicos y normas de reciprocidad estables, que vinculaban a las autoridades municipales con los dirigentes sociales, quienes cumplían un papel de intermediación entre aquéllos y la población $^{35}$. Esta estructura clientelista, construida en base a relaciones cotidianas que van más allá de lo utilitario, trascendió el liderazgo lavinista; proyectándose en dos elecciones sucesivas en las que fueron electos diferentes alcaldes apoyados por el mismo partido de Lavín.

Precisamente la existencia de una estructura clientelista e instrumentalizadora de los sectores populares ha sido usada para cuestionar el supuesto carácter "popular" al cual aspira la Unión Demócrata Independiente (UDI), el partido que ha defendido con mayor consistencia y lealtad la herencia político-institucional de la dictadura durante la transición democrática, siendo además el domicilio político de Lavín. ¿En qué medida la aplicación

\footnotetext{
33 Aníbal Pérez, “Clientelismo Político, Neoliberalismo y La Concertación: el 'guatón’ Pinto En El Municipio de Valparaíso 1990-1996,” Revista Divergencia, 3, 2013, 89-113; Aníbal Pérez, “¿UDI Popular? Los Campamentos y El Respaldo Electoral-Popular de Derecha. El Caso de Virginia Reginato En Viña Del Mar (2008-2013)",Izquierdas, 21, 2014, 1-30.

${ }^{34}$ Eugenio Tironi, Felipe Agüero y Eduardo Valenzuela, "Clivajes Políticos En Chile: Perfil Sociológico de Los Electores de Lagos Y Lavín”,Perspectivas, 5:1, 2001, 73-87.

${ }^{35}$ Evelyn Arriagada, "Clientelismo Político Y Participación Local: El Rol de Los Dirigentes Sociales En La Articulación Entre Autoridades Y Ciudadanos En Santiago de Chile”,Polis (Santiago), 12:36,2013, 15-38.
} 
de la etiqueta populista no contribuye a oscurecer el intento de construcción de hegemonía en los sectores populares por parte de ese partido? En necesario recordar que ya en la época de la dictadura, cuando la UDI fue fundada, entre sus principales ideólogos se tomó la decisión de disputarle a la izquierda el sector social que más se inclinó a apoyar las protestas violentas contra el régimen ${ }^{36}$, lo que posteriormente fue clave para el auge electoral de este partido en municipios pobres tradicionalmente controlados por la izquierda.

En una publicación reciente, el historiador Rolando Álvarez ${ }^{37}$ ha defendido la tesis de que tras el fín de la dictadura emergió una "nueva política" sustentada precisamente en los liderazgos de los órganos de poder local: "Las relaciones clientelares entre los alcaldes y sus respectivas comunidades, hizo que se tomaran en cuenta las demandas "desde abajo", las que privilegiaron un perfil de gestión comunal pragmática, alejada de los liderazgos político-ideológico tradicionales"38, así se fue fortaleciendo una faz "apolítica" y "gerencial" de los candidatos a alcaldes, donde "medidas contra la delincuencia, eficiencia en la gestión y la solución de problemas concretos, fueron los principales tópicos que configuraron la política municipal, que por su importancia ciudadana, terminó por trasladarse a nivel nacional".

Bajo esta interpretación, más que un "estilo político" cultivado por dirigentes locales, se trataría de la consolidación de una lógica política estructural: la municipalización de la política, de la cual Joaquín Lavín sería más producto que creador. Por otro lado, se resalta asimismo la importancia de la ciudadanía para demandar y promover esta nueva lógica. La política chilena de la post-dictadura no sería el resultado de la pasividad ciudadana, una de las tendencias analíticas que típicamente se deriva de la literatura sobre populismo ${ }^{39}$, sino más bien sería la consecuencia de un clientelismo que crece "desde abajo". Según el historiador chileno: "La despolitización de la sociedad, agobiada por años de represión y resocializada por el neoliberalismo, impuso un drástico cambio a la política chilena, que fue entendido por algunos dirigentes políticos, especialmente ligados al mundo de los gobiernos comunales" ${ }^{\circ 4}$. La ciudadanía habría tenido un papel activo en la despolitización chilena tras el fin de la dictadura, más que desinterés, fue un cambio en la agenda pública (seguridad, corrupción, etc.) demanda por un "sujeto neoliberal".

Podría trazarse un paralelo entre la municipalización de la política chilena y el paso, descrito por Manin ${ }^{41}$, de una democracia de partidos a una democracia de públicos, en el cual la erosión de las fidelidades partidarias reforzó la necesidad de dinamismos en la movilización de los electores, consolidando votos más fluctuantes y cruzados. Así, aunque los electores puedan estar desvinculados de los partidos, ellos los usan en determinadas

\footnotetext{
${ }^{36}$ Carolina Pinto, UDI La Conquista de Corazones Populares (1983 - 1987), Santiago, A\&V, 2006.

${ }^{37}$ Rolando Álvarez, “A nova política no Chile pós-ditatorial: Passividade cidadã ou clientelismo popular? (1990-1996)", Estudos Ibero-Americanos 40:1, 2014, 169-89.

${ }^{3}$ Álvarez, Op.cit., 172.

${ }^{39}$ Gino Germani, Política E Sociedade Numa Época de Transiçao: Da Sociedade Tradicional À Sociedade de Massas, Sao Paulo, Mestre Jou, 1973; Octavio Ianni, La Formación Del Estado Populista En América Latina, México, Serie Popular Era, 1975.

40 Álvarez, Op.cit., 186.

${ }^{41}$ Bernard Manin, “A Democracia Do Público Reconsiderada”,Novos Estudos - CEBRAP, 97, 2013, $115-27$.
} 
circunstancias mediante votos contextuales. Los partidos deben, por lo tanto, buscar constantemente el apoyo de los electores en cada votación, se deben reconfigurar de acuerdo con la composición de su público-objetivo, desideologizando su propuesta.

$\mathrm{Si}$ al fenómeno anterior, le agregamos lo que Richard Sennett ${ }^{42}$ define como el predominio contemporáneo de una sociedad íntima que debilita la esfera pública moderna, con grandes consecuencias políticas, por ejemplo: una exacerbación de los atributos personales de los políticos por sobre los idearios programáticos, con una consecuente confusión entre la vida privada y la vida pública de los representantes, con lo que se termina por privilegiar los códigos personales en detrimento de los impersonales; entonces bien nos podríamos preguntar si los cambios en el sistema político corresponden a una "desmodernización" de su funcionamiento que abre camino para un retorno populista o estamos, más bien, frente a una contemporaneización de sus dinámicas de acuerdo a las lógicas actuales de la política. Pareciera que lo que los investigadores de la política latinoamericana están llamando de nuevas formas de populismo en el continente lo que en otras geografías es identificado simplemente como cambios en la política.

¿Tiene sentido seguir en la búsqueda de un populismo histórico que se aproxime al ideal analítico del populismo?, ¿no será acaso más adecuado buscar dimensiones del populismo en la política chilena en vez de continuar rastreando la aparición de un populismo pleno? Recientemente Rodrigo Henríquez Vásquez ${ }^{43}$, desde una clave Laclauniana, ha reinterpretado la trayectoria del Estado social chileno a partir de las lógicas de politización popular y conformación de una idea de pueblo precisamente a partir de la consolidación de demandas sociales orientadas desde y hacia el Estado que contribuyeron a la solidificación de este último. Este fenómeno es definido por el autor como "frentepopulismo" y su emergencia fue posible gracias a la articulación de diferentes demandas sociales que confluyeron en la necesidad de potenciar el carácter interventor del Estado. Como en Laclau, el populismo importa aquí como lógica que posibilita el despliegue de lo político y no como un fenómeno históricamente distinguible.

Los trabajos locales sobre el populismo han sido un potente antídoto contra el mito de la excepcionalidad chilena, pero muchas veces esta operación termina por distorsionar fenómenos para hacerlos más homologables al populismo, con el riesgo de consolidar nuevas mistificaciones. Si bien es cierto que, como en un espejo retrovisor, los objetos pueden estar más cerca de lo que aparentan, la propia advertencia muestra que parte del fenómeno aparece con el propio instrumento. ¿Cuánto de la propia posible realidad del populismo en Chile es producto del papel jugado por las ciencias sociales y sus lentes analíticos sobre todo cuando el debate académico es transferido a la esfera pública?

\section{El retorno del espectro populista en la discusión pública chilena}

En el debate público del país andino, convive un discurso autocomplaciente del modelo político-económico basado en la estabilidad y en el respeto del consenso neoliberal y la potencial amenaza al mismo dada por formas conflictivas que podrían ser el preludio de un

\footnotetext{
${ }^{42}$ Richard Senett, El Declive Del Hombre Público, Barcelona, Editorial Península, 2002.

${ }^{43}$ Rodrigo Henríquez, En “Estado Sólido”: políticas y politización en la construcción estatal. Chile 19201950, Santiago, Ediciones UC, 2014.
} 
giro populista. La posibilidad del populismo aparece en estos debates como un recurso discursivo que busca proteger el modelo hegemónico de un desvío de este tipo. En este contexto, casi todas las semanas son publicadas entrevistas en los principales diarios del país en las cuales algún político acusa a un opositor de ser practicante de alguna forma de populismo. Las ciencias sociales han intervenido en esas controversias desde claves más bien problematizadoras del consenso neoliberal, por lo cual un análisis de cómo estas disciplinas han participado en las discusiones sobre el populismo no puede soslayar la dimensión pública de disciplinas como la sociología ${ }^{44}$; ni ignorar, de modo más general, la formación de un espacio público mediado por la intervención de cientistas sociales e intelectuales que procuran influir en los debates desde la legitimidad académica. Por ello, fueron escogidas por su ejemplaridad y oportunidad tres intervenciones públicas sobre este tópico. En primer lugar, un artículo publicado en la edición chilena de Le monde diplomatique por el entonces decano de la facultad de ciencias sociales de la Universidad de Chile en el momento que irrumpía el movimiento estudiantil del 2011, el antropólogo Marcelo Arnold. En segundo término, una columna más reciente de gran repercusión pública, aparecida en el diario español El País y firmada por uno de los investigadores chilenos que en los últimos años se ha transformado en una de las voces autorizadas en la academia sobre la temática populista, el sociólogo y politólogo Cristóbal Rovira ${ }^{45}$. Finalmente, desde una perspectiva más liberal, hemos decidido incorporar a dos analistas políticos que han tenido una extraordinaria repercusión en la prensa escrita mainstream hispanoamericana por su intención explícita de combatir el "giro populista" que marcó el ciclo de gobiernos de izquierda en América Latina que actualmente se encuentra en pleno declive, nos referimos a Axel Kaiser y Gloria Álvarez.

La aparición del movimiento estudiantil de 2011 tuvo un trazo paradojal para las perspectivas que apologizaron el tránsito chileno desde la dictadura a la democracia. El malestar estudiantil con lo que ellos denunciaban como la mercantilización de la educación coincidía con el momento de mayor expansión de la matrícula de la educación superior, gracias a la proliferación de universidades privadas y de créditos estatales para financiar los aranceles de las mismas. La elite chilena estaba desconcertada y buscaba explicaciones. En ese marco, Marcelo Arnold ${ }^{46}$ ensayó una respuesta, para él existiría un desacople entre el mejoramiento material producido por el crecimiento económico y las apreciaciones ciudadanas sobre la situación política y el bienestar personal, debido a la ampliación de expectativas provocadas por el crecimiento e incapacidad de las instituciones de procesar al mismo ritmos sus aspiraciones. La pregunta para él era si existían las bases para el populismo en el país. En Chile, a pesar del relato hegemónico sobre la transición, existirían componentes que podrían germinar en populismo: un sistema de representación electoral heredado de la dictadura que distorsionaba la real fuerza de las agrupaciones políticas ${ }^{47}$, limitando la competitividad y la diversidad de proyectos; la tecnificación de la política,

\footnotetext{
${ }^{44}$ Michael Burawoy, "Por una sociología pública”,Política y Sociedad, 42:1, 2005, 197-225.

${ }^{45}$ Cristóbal Rovira, "La Ceguera de La Elite Chilena,” El País, June 30, 2015, http://internacional.elpais.com/internacional/2015/06/30/actualidad/1435617430_119551.html

${ }^{46}$ Marcelo Arnold, “¿Existen Las Bases Para El Populismo En Chile?,” Le Monde Diplomatique, 07 2011, http://www.lemondediplomatique.cl/article1652,1652.html

${ }^{47}$ La eliminación del sistema electoral binominal fue una de las primeras reformas aplicadas por Michelle Bachelet en su segundo mandato.
} 
transformando espacios deliberativos en ámbitos de competencia técnica; el conocimiento público de las desigualdades sociales, como el correspondiente imperio de privilegios adscritos al origen y no al mérito; y finalmente la asimetría de poder entre capital y trabajo, mediante el debilitamiento de los sindicatos. El descrédito del sistema político y la desafección ciudadana sería el resultado de esta compleja combinatoria de factores, de tal manera que el cuestionamiento inicial se complementa con la siguiente respuesta: "¿qué faltaría para precipitar una fórmula populista en Chile? En mi impresión, no mucho, más bien muy poco. Bastaría solamente un eje articulador, un núcleo que haga girar en torno suyo algunos de los ingredientes disponibles" ${ }^{\text {"4 }}$.

Pocos años después, una nueva columna llegó a una conclusión similar, siendo ampliamente replicada en la prensa local, Cristóbal Rovira analizó el rechazo de la elite a todo tipo de reforma que aspire a responder a las exigencias de cambio abiertas por la movilización de 2011. Según él, la elite política y económica no estaría evaluando correctamente las señales dadas por la coyuntura política: la emergencia de una serie de escándalos que mostrarían la relación espuria entre poder y dinero estaría aumentado aún más la brecha entre el sistema político y la ciudadanía. Y la elite estaría respondiendo con las mismas lógicas de la transición democrática que estarían siendo puestas en entredicho.

En un trabajo anterior, el mismo Rovira ${ }^{49}$ había señalado que la transición chilena a la democracia habría sido el producto de un pacto inter-elites que consolidó un orden democrático de baja calidad, articulado a partir de tres ejes: la conformación de elites cerradas que monopolizan las decisiones colectivamente vinculantes; una ortodoxia de libre mercado sustentada en el poder de veto de los grupos económicos; y una tardía confrontación del legado autoritario. Esta limitación de la soberanía popular tendría como contrapartida la consolidación y estabilidad del sistema político. Así, la principal virtud de la transición, la estabilidad, habría sido a costa del principal defecto: una democracia de baja intensidad. Sin embargo, aunque fuese tolerada y aceptada por la ciudadanía, esa dinámica ya no tendría más respaldo y la elite habría sido incapaz de adaptarse a los nuevos tiempos. De ahí se desprende la alarma:

Puede que ya sea demasiado tarde para que la elite remedie su accionar. Es altamente probable que las confianzas rotas ya no puedan recuperarse. De ser esto cierto, la irrupción del populismo está a la vuelta de la esquina. Pues lo propio del discurso populista es la distinción entre un establishment corrupto y un pueblo soberano que demanda el irrestricto ejercicio de la voluntad general. La ceguera de la elite chilena está pavimentando el camino para el surgimiento del populismo. No aleguen después que nadie les advirtió. ${ }^{50}$

Un tercer caso muy ilustrativo del tipo de análisis que se difunden en los medios de mayor circulación es el de Axel Kaiser y Gloria Álvarez, analistas políticos chileno y guatemalteca, respectivamente. En varias columnas de opinión, eventos, seminarios y, más

\footnotetext{
${ }^{48}$ Arnold, Op.cit.

${ }^{49}$ Cristóbal Rovira, "Chile: Transición Pactada y Débil Autodeterminación Colectiva de La Sociedad”,Revista Mexicana de Sociología,69:2, 2007, 343-72.

${ }^{50}$ Rovira, "La Ceguera de La Elite Chilena."
} 
recientemente con la publicación de un libro $^{51}$ muy difundido y hasta comentado por el influyente novelista liberal Mario Vargas Llosa los autores no cesan de divulgar su credo antipopulista primero en Chile y luego en todo el mundo de habla hispana. En clave regional, pero que se replica predominantemente en Chile, los autores identifican al menos 5 desviaciones que serían propias de los populismos sean éstos de izquierda o de derecha:

Sin duda, existen otras, pero nos pareció que estas cinco son las más recurrentes y peligrosas para una democracia liberal basada en mercados competitivos. Todas ellas se basan en una serie de mentiras, falacias e incoherencias cuya refutación hemos intentando realizar con el fin de avanzar en un lenguaje claro que nos permita estar alertas sobre la forma en que los populistas, ideólogos y demagogos de diversas tribus buscan engañarnos. ${ }^{52}$

En este sentido, Kaiser y Alvarez destacan lo que llaman como la idolatría del Estado, como la primera desviación o engaño, que llevaría a otorgar todo el poder al Estado frente al mercado y a la iniciativa individual. Le sigue el victivismo, particularmente generalizado en América Latina que lleva a culpar a otros de los males e incapacidades propios. Continúa en la paranoia antineoliberal, que utilizaría al Neoliberalismo como una etiqueta a la que se le acusa de todos los males imaginables. La cuarta desviación que destacan es la pretensión democrática, donde el populismo adquiriría sus mayores dotes "tramposos": si en otros momentos históricos las experiencias populistas habrían alcanzado formas autoritarias y hasta totalitarias buscando llegar al poder por la vía armada, hoy en día pretenderían disputar el mismo terreno de la institucionalidad republicana en una batalla que es más de las ideas (y de la hegemonía cultural) que de la violencia. En último lugar colocan a la obsesión igualitaria propia de fascistas como Hitler como de socialistas (sic) tales como Pablo Iglesias, Fidel Castro, Hugo Chávez o Néstor Kirchner. La obsesión igualitaria culminaría en una fantasía mediante la cual se justifica el odio de clase mientras una nueva casta en el poder se enriquecería ilimitadamente en regímenes corruptos dejando al pueblo, al que se decía redimir, en el abandono, la miseria y el engaño. ¿Dónde queda Chile en este apocalipsis? Por un lado, su mentado excepcionalismo no parece librarlo completamente del peligro populista. El engaño estaría siendo facilitado por las reformas que quiere introducir el gobierno de la Nueva Mayoría (al fin de cuentas, no es casual que la presidenta Michelle Bachelet aparezca en la tapa del libro). Por otro, Chile es el contraejemplo, el antídoto frente el engaño populista mostrando lo fútil y superfluo de las desviaciones populistas con la evidencia que representa los logros del "modelo chileno": el Neoliberalismo también puede servir para superar la pobreza, el Estado no es el principal agente de desarrollo y crecimiento, sino al contrario, pues la apertura comercial y la orientación primario-exportadora no conducen inevitablemente a la explotación. Al fin de cuentas de lo que se trata es de defender las instituciones fuertes y un crecimiento que por sus logros no merecería ser puesto en el cadalso de la igualdad, evitando el acecho de los embates y engaños populistas que, "de este modo se aprovechan de utilizar una etiqueta que

\footnotetext{
${ }^{51}$ Axel Kaiser y Gloria Álvarez, El engaño populista, ¿Por qué se arruinan nuestros países y cómo rescatarlos?, Bilbao, Deusto, 2016.

${ }^{52}$ Axel Kaiser y Gloria Álvarez, "El Populismo En Cinco Desviaciones”, El Mundo, 13 de mayo, 2016. http://www.elmundo.es/cronica/2016/05/13/572cdc34e5fdead3148b45a8.html
} 
ha probado ser muy efectiva en desprestigiar instituciones serias y políticas económicas productivas para la población, como muestra irrefutablemente el caso de Chile" ${ }^{\text {53 }}$.

De este modo, los autores - aun con toda la pátina aggiornada de eventos, redes sociales y cobertura por parte de los medios dominantes de la región (el Grupo de Diarios América) - vuelven a caer en el lugar común de confundir populismo con demagogia y a un tipo de demagogia que es más bien mera dilapidación de recursos económicos. Así se sitúan en la senda de otro estudio muy influyente: el de Dornbusch y Edwards ${ }^{54}$, de enorme influencia en la región y en Chile en particular, de lectura obligatoria en varias universidades convirtiéndose en el dogma para interpretar correctamente las vinculaciones entre economía y política y la lucha contra la pobreza y la desigualdad dentro de lo que se considera racionalmente posible y justo. Así, los autores, junto a la Derecha económica en la región, continúan considerando cualquier política económica con tintes de distribucionismo y regulación como populismo.

\section{Conclusiones}

Es toda una ironía, pero quizás confirmando cierto excepcionalismo chileno, la preocupación académica y pública ante el populismo parece estar mucho más presente que en el resto del continente. Ciertamente que está ocurriendo un cambio de ciclo o al menos un crepúsculo postneoliberal en la región, por lo que el fantasma populista ya no asusta como en la década pasada. Más aún, en este momento los dardos más punzantes que recibe provienen más del campo "progresista" que de la Derecha y los medios dominantes. Estos últimos tratan de debilitar a los gobiernos postneoliberales aún en el poder o de quejarse por la herencia recibida. En cambio, los que se situaban a la izquierda de estos experimentos postneoliberales creen que ha llegado la hora del ansiado ajuste de cuentas sobre todo con los casos menos extremos y más devaluados en este momento (Argentina y Ecuador). Así por ejemplo, Maristella Svampa no deja de repartir sus diatribas contra los populismos de clase media y el Kirchnerismo en particular:

Mientras los populismos plebeyos hicieron una apuesta por la participación desde abajo, muchas veces desordenada o anárquica (sobre todo en Venezuela, con rasgos más corporativos en Bolivia) o bien buscaron crear una nueva estructura político-jurídica para dar cuenta de una realidad plural (Estado plurinacional), los populismos de clases medias solo han apuntado a hacer de la participación una suerte de declamación retórica, sustituyendo la innovación institucional y la búsqueda de un horizonte de igualdad por el paradigma más confuso y acotado de la 'inclusión social' ${ }^{55}$

O bien Alberto Acosta, quien fuera presidente de la Asamblea Constituyente del Ecuador y ahora califica a Rafael Correa como "el caudillo del Siglo XXI", quien se habría

\footnotetext{
${ }^{53}$ Kaiser y Álvarez, op.cit.

${ }^{54}$ RüdigerDornbusch y Sebastián Edwards(eds),The Macroeconomics of Populism in Latin America, Chicago, Chicago University Press, 1991.

${ }^{55}$ MaristellaSvampa, Debates Latinoamericanos. Indigenismo, Desarrollo, Dependencia, Populismo, Buenos Aires,Edhasa, 2016, 475-476.
} 
ido distanciando sistemáticamente de sus orígenes concentrándose "simplemente" en modernizar el capitalismo en Ecuador. En el plano regional agrega:

Lamentablemente esos gobiernos, unos más y otros menos, no han superado las lógicas autoritarias, no han posibilitado la construcción de esquemas participativos en la toma de decisiones, no han logrado adecuados niveles de eficiencia, tampoco han eliminado las viejas prácticas corruptas; y, a la postre, han terminado por ser simplemente gestores de esquemas modernizantes, dentro del capitalismo periférico, es decir a tono con los cambios que se están dado en la división internacional del trabajo. ${ }^{56}$

Además de esta crítica al estilo de conducción, otro blanco es el de la cuestión del neo-extractivismo: es decir la no superación e incluso la consolidación del extractivismo de las materias primas orientadas a la exportación como modelo de acumulación predominante, pero actualmente conducido desde el Estado y legitimado con fines redistributivos:

Comencemos por recordar que bajo los anteriores contextos políticos, las corrientes progresistas y de izquierda, denunciaban que el extractivismo contribuía a generar la pobreza, las economías de enclave eran vistas como algo negativo, y por lo tanto, se buscaban alternativas de salida a esas condiciones. Bajo los gobiernos progresistas poco a poco se está solidificando un nuevo discurso por el cual el extractivismo ahora pasa a ser una condición necesaria para combatir la pobreza. Hay una reversión de aquella vieja relación, y donde en el pasado había una oposición, en la actualidad es visto como positivo y se convierte en una condición de necesidad para el desarrollo. ${ }^{57}$

Éstas distan de ser las coordenadas del debate en Chile. En general, las preocupaciones no son tan amplias y agudas sino que se mantiene la mirada negativa respecto del populismo con un ánimo sanitarista: una enfermedad a combatir o al menos generar los antídotos posibles para evitar el contagio. En este sentido y como hemos demostrado en esta revisión, el debate y las preocupaciones se siguen moviendo dentro de la semántica del riesgo ante la irracionalidad económica asociada al populismo o bien como un problema propio del sistema político relacionado con la inestabilidad institucional y con los liderazgos personalistas.

Las movilizaciones sociales recientes han cambiado la política chilena y dejado en evidencia los déficits democráticos del modelo chileno ${ }^{58}$. Las ciencias sociales han acompañado este giro recuperando, entre otras categorías, el concepto de populismo en los

\footnotetext{
${ }^{56}$ Alberto Acosta, “Alberto Acosta: Molesta e Indigna El Estilo Autoritario yCaudillesco de Correa.” El Mundo, 12 de agosto, 2015.

http://www.elmundo.es/internacional/2015/08/12/55c21ad7268e3ec5218b457e.htmlEn negrita en el original.

${ }^{57}$ Eduardo Gudynas, "El Nuevo Extractivismo Progresista En América Del Sur. Tesis Sobre Un Viejo

Problema Bajo Nuevas Expresiones",VV.AA., Colonialismos Del Siglo XXI. Negocios Extractivos Y Defensa Del Territorio En América Latina, Icaria, Barcelona, 2011, 87.

${ }^{58}$ Alexis Cortés, "Chile En La Encrucijada de Un Nuevo Ciclo”, Cadernos de Trabalho NETSAL, 3:7, 2015, $1-42$.
} 
debates públicos. El desafío, sin embargo, es no leer todo intento de tránsito desde la irrupción de ciudadanía instituyente a ciudadanía instituida ${ }^{59}$ como una reedición populista; sin subestimar, al mismo tiempo, el potencial correctivo de los debates sobre populismo para visibilizar las derivaciones negativas de la clausura e indiferencia del sistema político frente a las demandas sociales emergentes. Chile no está ni tan lejos ni tan cerca del populismo y este último no se puede comprender sin considerar los usos y abusos que las ciencias sociales hacen de ese concepto.

\section{Referencias}

Fuentes Impresas

Álvarez, Rolando, “A nova política no Chile pós-ditatorial: Passividade cidadã ou clientelismo popular? (1990-1996)”, Estudos Ibero-Americanos, 40:1, 2014, 169-89,doi:10.15448/1980864X.2014.1.14517.

Arriagada, Evelyn, “Clientelismo Político Y Participación Local: El Rol de Los Dirigentes Sociales En La Articulación Entre Autoridades Y Ciudadanos En Santiago de Chile”,Polis (Santiago), 12: 36, 2013, 15-38, doi:10.4067/S0718-65682013000300002.

Barozet, Emmanuelle, "Movilización de Recursos Y Redes Sociales En Los Neopopulismos: Hipótesis de Trabajo Para El Caso Chileno”,Revista de Ciencia Política (Santiago), 23:1, 2003, 3954, doi:10.4067/S0718-090X2003000100004.

—_, "Populismo regional y estado en Chile",Estudios Interdisciplinarios de América Latina y el Caribe, 19: 2, 2008, 45-60.

Burawoy, Michael, "Por una sociología pública”,Política y Sociedad, 42: 1, 2005, 197-225.

Castañeda, Jorge, “Latin America’s Left Turn”,Foreign Affairs, 85: 3, 2006.

Castells, Manuel, Globalización, Desarrollo Y Democracia: Chile En El Contexto Mundial.

Santiago, Fondo de Cultura Económica, 2005.

Cortés, Alexis, “Chile En La Encrucijada de Un Nuevo Ciclo", Cadernos de Trabalho NETSAL, 3: 7, 2015, 1-42.

Cousiño, Carlos, “Populismo Y Radicalismo Durante El Gobierno de La Unidad Popular”,Estudios Públicos, 82, 2001, 189-202.

de la Torre, Carlos, "El Populismo Latinoamericano: Entre La Democratización Y El Autoritarismo",Nueva Sociedad, 247, 2013, 120-37.

\footnotetext{
${ }^{59}$ José Maurício Domingues, “Las Movilizaciones de Junio de 2013: ¿explosión Fugaz o Novísima Historia de Brasil?",OSAL Observatorio Social de América Latina, 14: 34, 2013, 62-72.
} 
Dockendorff, Andrés y Vanessa Kaiser, "Populismo En América Latina. Una Revisión de La Lieratura Y La Agenda”, Revista Austral de Ciencias Sociales, 17, 2009, 75-100.

Domingues, José Maurício, “Las Movilizaciones de Junio de 2013: ¿explosión Fugaz O Novísima Historia de Brasil?”,OSAL Observatorio Social de América Latina, 14: 34, 2013, 62-72.

Dornbusch,Rüdigery Sebastián Edwards (eds), The Macroeconomics of Populism in Latin America, Chicago, Chicago University Press, 1991.

Fernández, Joaquín, El Ibañismo (1937-1952): Un Caso de Populismo En La Política Chilena, Santiago de Chile, Instituto de Historia PUC Chile, 2007.

Garretón, Manuel Antonio, Dictaduras Y Democratización, Santiago, FLACSO, 1984.

Germani, Gino,Política E Sociedade Numa Época de Transiçao: Da Sociedade Tradicional À

Sociedade de Massas, Sao Paulo, Mestre Jou, 1973.

Giddens, Anthony, Las Nuevas Reglas Del Método Sociológico, Buenos Aires,Amorrortu, 1987.

Ianni, Octavio, La Formación Del Estado Populista En América Latina, México, Serie Popular Era, 1975.

Grugel, Jean, "Populism and the Political System in Chile: Ibañismo (1952-1958)" Bulletin of Latin American Research, Vol. 11, No. 2 (Mayo, 1992), 169-186

Gudynas, Eduardo, "El Nuevo Extractivismo Progresista En América Del Sur. Tesis Sobre Un Viejo Problema Bajo Nuevas Expresiones”,VV.AA., Colonialismos Del Siglo XXI. Negocios Extractivos Y Defensa Del Territorio En América Latina, Icaria, Barcelona, 2011, 87.

Henríquez, Rodrigo, En "Estado Sólido”: politicas y politización en la construcción estatal. Chile 1920-1950, Santiago, Ediciones UC, 2014.

Kaiser, Axel y Gloria Álvarez, El engaño populista, ¿Por qué se arruinan nuestros países y cómo rescatarlos?, Bilbao, Deusto, 2016.

Laclau, Ernesto, La Razón Populista, Bueno Aires, FCE, 2005.

Mackinnon, María Moira y Mario Alberto Petrone: "Los complejos de la cenicienta", introd. a Mackinnon y Petrone (Eds.): Populismo y Neopopulismo en América Latina. El problema de la Cenicienta. Buenos Aires, Eudeba, 1998, 11-55.

Manin, Bernard, “A Democracia Do Público Reconsiderada”,Novos Estudos - CEBRAP, 97,2013, 115-27,doi:10.1590/S0101-33002013000300008.

Pelfini, Alejandro, "Megatrend Global Populism? From South America to the Occupy Movement", Alexander Lenger y Florian Schumacher (eds.), Understanding the Dynamics of Global Inequality: Social Exclusion, Power Shift, and Structural Changes, Berlin - Heildelberg, Springer, 2015, 199211. 
—_, 'Uso Inflacionario de Los Conceptos 'Elite' Y 'Populismo': Desventuras Recientes de Dos Categorías Claves de Las Ciencias Sociales Latinoamericanas”, Tomás Ariztía (ed.), Produciendo Lo Social: Usos de Las Ciencias Sociales En El Chile Reciente, Santiago, Ediciones Universidad Diego Portales, 2012, 197-217.

Pérez, Aníbal, “Clientelismo Político, Neoliberalismo Y La Concertación: el 'guatón’ Pinto En El Municipio de Valparaíso 1990-1996”,Revista Divergencia, 3, 2013, 89-113.

_. “¿UDI Popular? Los Campamentos Y El Respaldo Electoral-Popular de Derecha. El Caso de Virginia Reginato En Viña Del Mar (2008-2013)",Izquierdas, 21, 2014, 1-30.

Pinto, Carolina, UDI La Conquista de Corazones Populares (1983 - 1987), Santiago, A\&V, 2006.

Ramos, Claudio, "Datos Y Relatos de La Ciencia Social Como Componentes de La Producción de Realidad Social”, Convergencia, 21: 66, 2014, 151-77.

Riveros, Claudio, “Populismo, democracia y democratización”. Persona y Sociedad, 29:3, 2015, 103-126.

Roitman Rosenmann, Marcos, Pensar América Latina. El Desarrollo de La Sociología Latinoamericana, Buenos Aires, CLACSO, 2008.

Rovira Kaltwasser, Cristóbal, "Chile: Transición Pactada Y Débil Autodeterminación Colectiva de La Sociedad”,Revista Mexicana de Sociología, 69 (2), 2007, 343-72.

—, "The Ambivalence of Populism: Threat and Corrective for Democracy",Democratization, 19: 2, 2012, 184-208, doi:10.1080/13510347.2011.572619.

Sennett, Richard, El Declive Del Hombre Público,Barcelona, Editorial Península, 2002.

Simbürger, Elisabeth, "The Labor of Knowledge in the Making of the Social Sciences", International Sociology, 29:2, 2014, 89-97, doi:10.1177/0268580914524108.

Simões Reis, Guilherme. "Um Século de Política Europeia (Contado Como Se Fosse Na América Do Sul)", Insight Inteligência, 16: 64, 2014, 91-98.

Svampa, Maristella, Debates Latinoamericanos. Indigenismo, Desarrollo, Dependencia, Populismo, Buenos Aires, Edhasa, 2016.

Tironi, Eugenio, Felipe Agüero y Eduardo Valenzuela, “Clivajes Políticos En Chile: Perfil Sociológico de Los Electores de Lagos Y Lavín”,Perspectivas, 5:1, 2001, 73-87.

Touraine, Alain, “Éxitos Y Límites de La Democratización En América Latina”,Estudios Sociológicos, 16: 48, 1998, 745-60.

Valdivia, Verónica, "Yo, el León de Tarapacá”, Historia, Vol. 32. 1999: 485-551

Weyland, Kurt, "Clarifying a Contested Concept: Populism in the Study of Latin American Politics", Comparative Politics, 34:1, 2001, 1-22. 


\section{Fuentes Digitales}

Acosta, Alberto, "Molesta e indigna el estilo autoritario y caudillesco de Correa, Entrevista a Alberto Acosta", El Mundo, España, 08/12/2015,http://www.elmundo.es/internacional/2015/08/12/55c21ad7268e3ec5218b457e.html Arnold, Marcelo, “¿Existen Las Bases Para El Populismo En Chile?”,Le Monde Diplomatique, 07/ 2011, http://www.lemondediplomatique.cl/article1652,1652.html

Dussel, Enrique, “Cinco Tesis Sobre El 'populismo”, Iztapalapa, 2007. http://enriquedussel.com/txt/Populismo.5\%20tesis.pdf Kaiser, Axel y Gloria Álvarez, "El Populismo En Cinco Desviaciones”, El Mundo, 13 de mayo, 2016. http://www.elmundo.es/cronica/2016/05/13/572cdc34e5fdead3148b45a8.htmlRovira, Cristóbal, “La Ceguera de La Elite Chilena”,El País,30 de junio, 2015.

http://internacional.elpais.com/internacional/2015/06/30/actualidad/1435617430 119551.html 